\title{
Isallo stress analysis of the Rat Islands (Alaska) earthquake sequence
}

\author{
R. E. RANKEN - A. E. SChEIDEGGER $\left({ }^{*}\right)$
}

Ricevuto il 29 Luglio 1968

Summary. - The two fault planes furnished by the fault plane solutions of earthquakes of the Rat Islands sequence were treated like the conjugate fault planes of geological surface faults, and an isallo stress analysis was made thereon. It is shown that the latter yields results which are in conformity with data from other sources. A discussion of the tectonic stress system in the Rat Islands region of Alaska is given.

Riassunto. - I due piani di faglia ricavati dai calcoli sul meccanismo all'ipocentro della serie di terremoti delle Isole Rat, sono trattati con lo stesso metodo usato per faglie visibili alla superficie (" isallo stress method "). Questa analisi conduce a risultati analoghi a quelli ottenuti usando dati di diversa origine. Viene fatta anche una discussione sulle caratteristiche tettoniche della regione delle Isole Rat in Alaska.

\section{INTRODUCTION.}

During the past ten years or so, a method termed " isallo stress analysis" has been developed to determine the tectonic stress field of an area from an investigation of the traces of conjugate fault systems at the Earth's surface $\left({ }^{1}\right)\left({ }^{2}\right)\left({ }^{3}\right)$.

The idea is that angle $\gamma$ between conjugate surface faults (the "compressional angle ") facing the principal horizontal stress (PHS) direction is indicative of the type of stress field $\left(^{4}\right)$ that is present in the area.

(*) University of Illinois, Urbana. 
It is well known it is possible, from an evaluation of the first onsets arising at seismic stations due to an earthquake, to determine a "fault plane solution" for that earthquake. All such fault plane solutions, as long as they are based solely on first ( $P$-wave) onsets, are ambiguous to the extent that two, rather than one, possible fault planes are obtained. On the other hand, a fault plane solution yields unambiguously the axis of largest compression $(P)$, the axis of least compression $(T)$ and the intermediate principal axis $(B)$ of the stress system operating at the focus of an earthquake. The idea is now to treat the surface traces of the two potential "fault planes " of an earthquake in the same fashion as the traces of a conjugate fault system and to apply isallo stress analysis to it.

In order to proceed in this fashion, a single earthquake is evidently insufficient. It is necessary that one have a series of well-determined fault plane solutions of earthquakes with well-determined epicenters closely spaced in the same area. The aftershock sequence of the Rat Islands earthquake starting on February 6, 1965 fulfills this requirement, inasmuch as Stauder $\left(^{5}\right)$ has published accurate epicenters and fault plane solutions thereof. Figure 1 shows the location of the main shock and some of the larger aftershocks. The larger symbols indicate the aftershocks for which fault plane solutions were obtained by Stauder. Table 1 lists the data obtained for these solutions.

As noted in this table, the aftershocks listed occurred over an interval of 18 months. Figure 2 illustrates the temporal sequence of the fault plane solutions as well as their locations relative to the main geological features of the area.

\section{ISALLO STRESS APPLICATION.}

Using each fault plane solution's plane I and plane II it is possible to obtain two intersecting lines which can be said to correspond to the intersecting surface fracture traces used in isallo stress analysis. Figure 3, obtained from the seismic data, can be considered equivalent to a lineament map depicting intersecting surface fault traces.

The next task is to choose an appropriate $P H S$ direction, so that it is known which of the two possible angles in the intersecting " fault traces " is the compressional angle $\gamma$.

Consideration of the following factors led to the selection of $\mathrm{N} 40 \mathrm{~W}$. S40E as the PHS direction. Stauder $\left(^{5}\right)$ mentions that it is reason- 


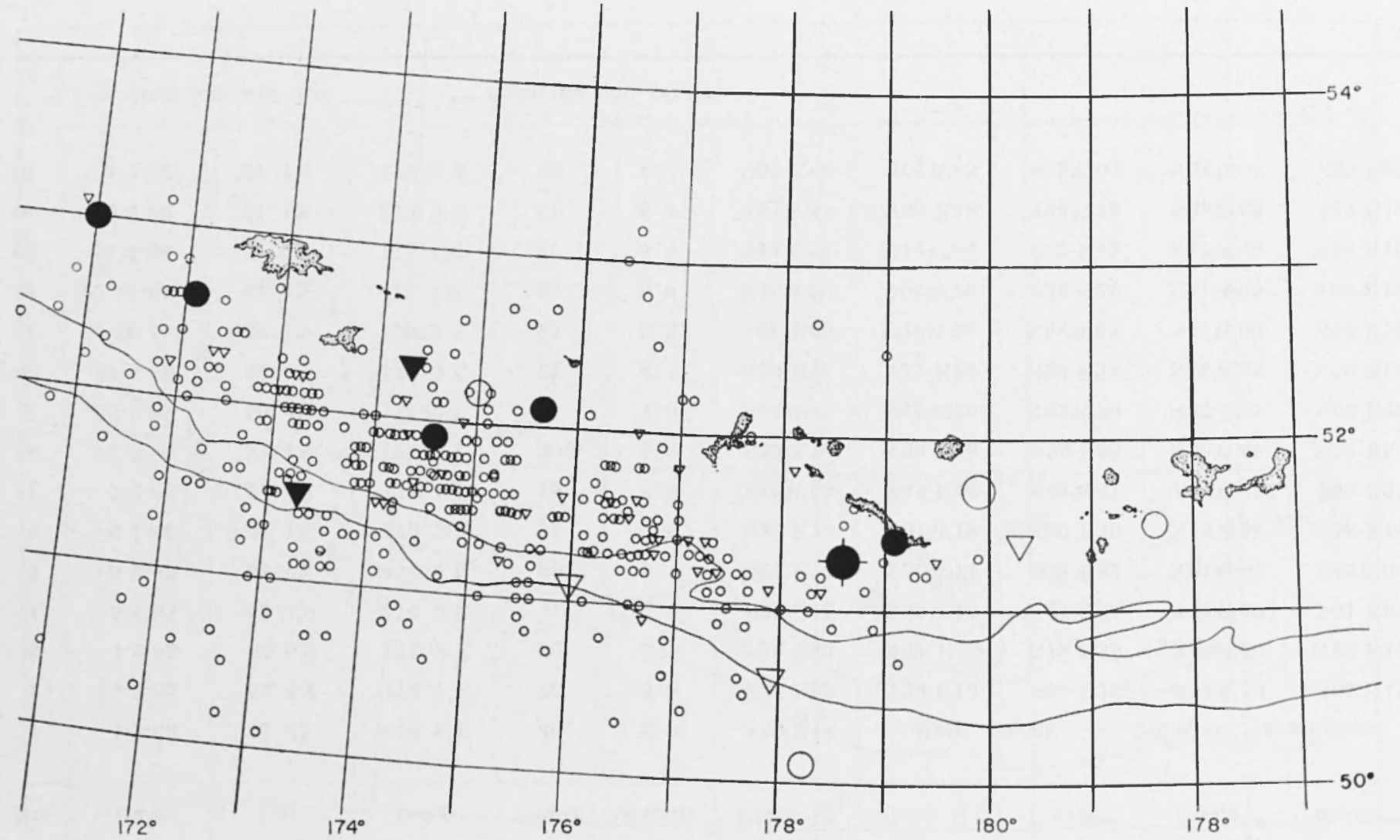

Fig. 1 - The 4 February 1965 Rat Islands earthquake aftershock locations (large symbols indicate aftershocks for which fault plane solutions were obtained: solid symbols represent aftershocks of the first three days: open symbols represent aftershocks occurring between $30 \mathrm{March} 1965$ and 4 July 1966). (dfter stauder, 1968). 
TABLE 1

Seismic Data for the 4 February 1965 Rat Islands Earthquake Aftershocks (after stauder, 1968).

\begin{tabular}{|c|c|c|c|c|c|c|c|c|c|c|}
\hline No. & Date & Lat. & long. & Depth & Magnit. & Plane I* & Plane II* & $P$-axis** & $T$-axis** & $B$-ilxis** \\
\hline & & & & & & & \multirow{2}{*}{\multicolumn{2}{|c|}{ Main Shock }} & \multirow{2}{*}{\multicolumn{2}{|c|}{ Solution Incomplete }} \\
\hline 1 & $4 \cdot 2-65$ & $51.3 N$ & $178.6 \mathrm{E}$ & 40 & 6.0 & S30 E7s & & & & \\
\hline 2 & $4-2-65$ & $52.6 \mathrm{~N}$ & $172.1 \mathrm{E}$ & 25 & 5.8 & $\$ 35 \mathrm{~K} 83$ & $\times 29 \mathrm{E} 15$ & $\therefore 21 \mathrm{E} 36$ & N5IW50 & N57 E13 \\
\hline 3 & $4-2.65$ & $53.0 \mathrm{X}$ & $171.0 \mathrm{E}$ & 30 & 5.7 & $\$ 32 \mathrm{k} 83$ & N33 EIT & $\$ 19$ E35 & $\mathrm{N}+8 \mathrm{~W} 50$ & X60 E 14 \\
\hline 4 & $5-2-65$ & $52.3 N$ & $174.3 \mathrm{E}$ & 41 & 5.9 & $\$ 39$ E 75 & N35W'15 & $537 \mathrm{E} 30$ & $x+1 W 59$ & N51 E01 \\
\hline 5 & $5-2-65$ & $51.9 \mathrm{~N}$ & $174.6 \mathrm{E}$ & 35 & 5.7 & $827 \mathrm{E77}$ & S50 Wr & $\$ 32 \mathrm{E} 32$ & N2IW57 & S62W04 \\
\hline 6 & $6-2-65$ & $52.1 X$ & $175.7 \mathrm{E}$ & 35 & 5.9 & S38 E:75 & NolW' & S29 E30 & N50W58 & X55 $\mathrm{E} 10$ \\
\hline 7 & $7-2-65$ & $5 \mathrm{I} \cdot \mathrm{+N}$ & $173 .+\mathrm{E}$ & 40 & 6.0 & \$16W53 & N58 E+5 & $x+31167$ & $53+1103$ & $\$ 58 \mathrm{E} 23$ \\
\hline 8 & $7-2-65$ & $51.4 x$ & $179.1 \mathrm{E}$ & 30 & 5.3 & S39 E74 & N20 E 16 & \$35 E30 & $N+6 \mathrm{~W} 59$ & X52 E04 \\
\hline 9 & $30-3-65$ & $50.6 \mathrm{~N}$ & $177.9 \mathrm{E}$ & 51 & 7.0 & $\mathrm{SI}+\mathrm{W}_{4}$ & $\times 52 W 50$ & N62W70 & N33 E01 & \$56 K20 \\
\hline 10 & $23-5 \cdot 65$ & $52.2 \mathrm{~N}$ & $175.0 \mathrm{E}$ & 22 & 6.1 & $835 \mathrm{E} 75$ & $\mathrm{~N} 12 \mathrm{E} 22$ & $522 \mathrm{~F} 28$ & N56W58 & N59 E15 \\
\hline 11 & $1-10-65$ & $50.1 N$ & $178.2 \mathrm{E}$ & 23 & 6.3 & S05 E50 & N40W50 & N68W65 & SIFWo0 & N73 E25 \\
\hline 12 & $22-11-65$ & $51.4 N$ & $179.7 \mathrm{~W}$ & 40 & 5.9 & $\triangle 35$ E 70 & No611222 & $826 \mathrm{E} 24$ & N5וW63 & N59 Eı \\
\hline 13 & $15-5-66$ & $51.5 \mathrm{X}$ & $178 .+W$ & 31 & 5.8 & s44 E61 & NוI34 & \$32 E15 & $\times 82 W 68$ & $\mathrm{~N}+5 \mathrm{E} 16$ \\
\hline 14 & $2-6-66$ & $51.1 \times$ & $176.0 \mathrm{E}$ & 41 & 6.0 & S3IW5I & ऽ50 E+0 & N24W78 & s39W02 & \$52 k10 \\
\hline 15 & $+-7-66$ & $51.7 N$ & $179.9 \mathrm{E}$ & 13 & 6.2 & X97 E85 & 5071185 & \$52W0I & N38W07 & $\$ 39 \mathrm{E} 83$ \\
\hline
\end{tabular}




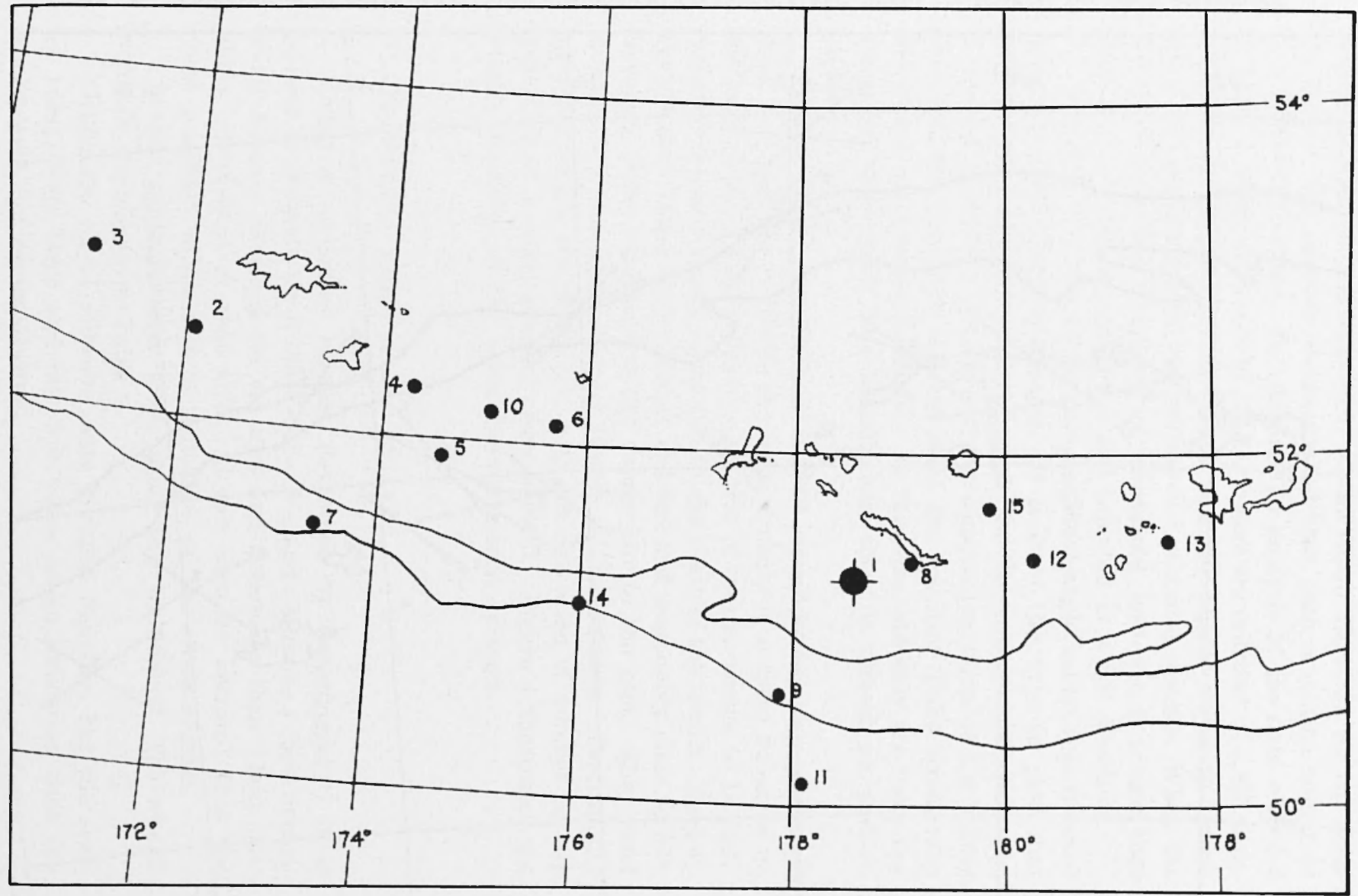

Fig. 2 - Occurrence sequence of the 4 February 1965 Rat Islands earthquake aftershocks. (After Stauder, 1968). 


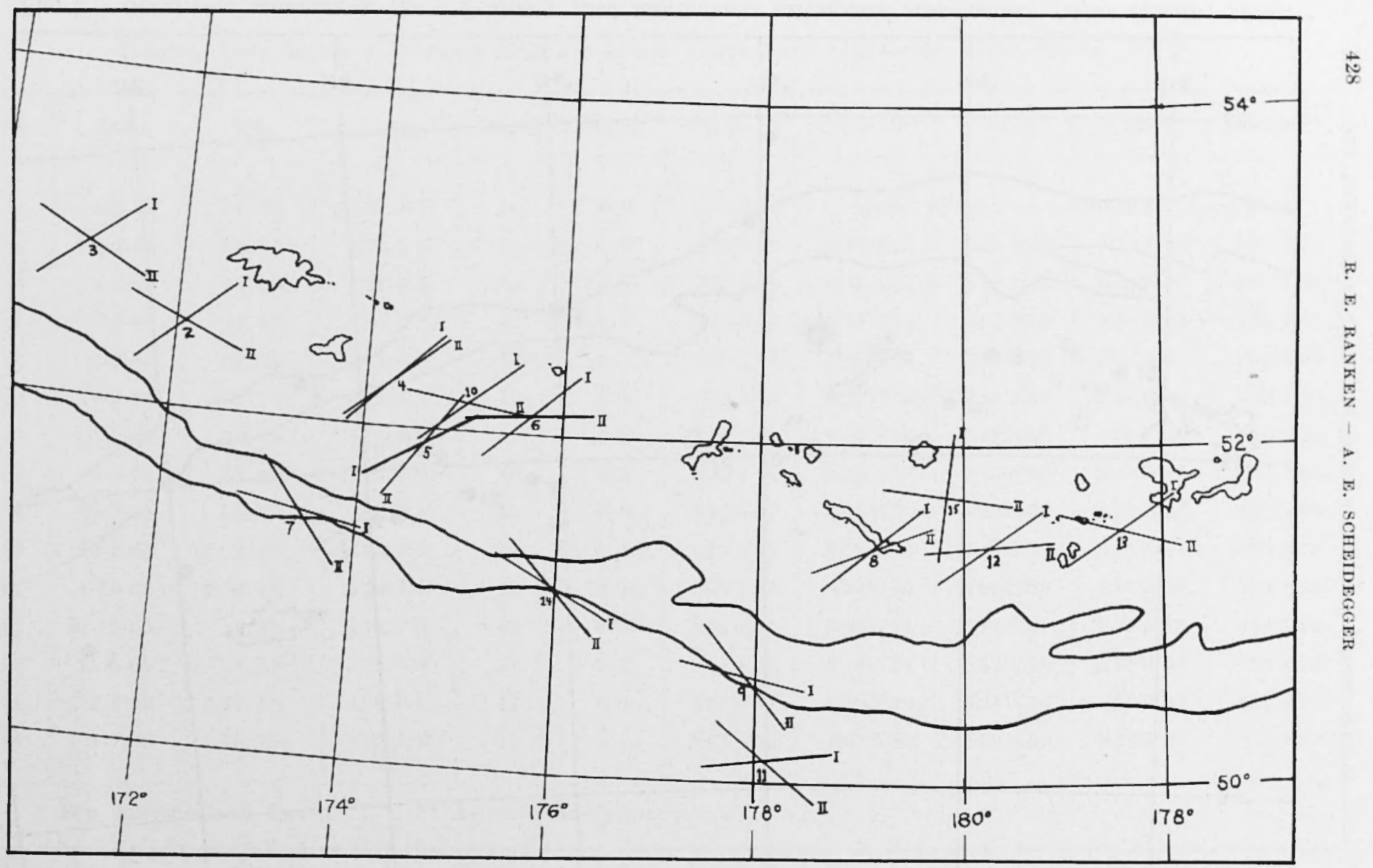

Fig. 3 - Orientation of earthquake fault plane solution plane I and plane II (strikes) for each aftershock. 
able to assume an underthrusting of the island are block by the oceanic block. His analysis demonstrated that such a motion would be in a NW-SE direction. In addition, an analysis of the data recorded in Table 1 shows that nine of the $14 P$-axes are oriented in a SE direction. Of the remaining five $P$-axes, four dip almost vertically downward. These can hardly be considered horizontal stresses. When the $B$-axes of these four solutions are considered, however, it is seen that they are very nearly horizontal and oriented in a SE direction.

Figure 4 is a plot of the compressional angle values that resulted from the $P H S$ direction chosen. It is from this type of plot that isallo stress maps are usually drawn. In the present case, however, it was not possible to do this. In any application where so few values are available over such a large area, the resulting isallo stress map should not be considered reliable. In this case, not only are there few values to work with, but, in addition, there is almost no pattern visible.

If the $0^{\circ}-45^{\circ}, 45^{\circ}-135^{\circ}, 135^{\circ}-180^{\circ}$ classification of $\gamma$ values is used, it is possible to divide the area of study into three subareas on the basis of the $\gamma$ values shown. An area of tension seems to be indicated by the four values along and to the south of the trench. The two westernmost values are relatively isolated and reasonably close to $90^{\circ}$, especially when compared to the values just to the east. They tend to indicate a transcurrent stress system in that subarea. The remaining values along the island arc, with the exception of number 15 , are indicative of a compressional stress system. Figure 4 illustrates the relative positions of the three different stress systems.

\section{Statistical " BEST AXIS " ANALYSIS.}

Using a statistical method developed by Scheidegger $\left(^{8}\right)$ it is possible to evaluate all of the $P-, T-, B-$, and "Motion-" (best normal to all $B$ ) axes obtained for an area and determine their "best possible " orientations in that area. It can then be assumed that the "best possible " orientation is indicative of the stress system.

Several attempts were made using this technique. The results obtained are shown in Table 2.

Originally, all 14 solutions were grouped together, but the scatter values were large and this was taken as an indication that the results were not representative. 


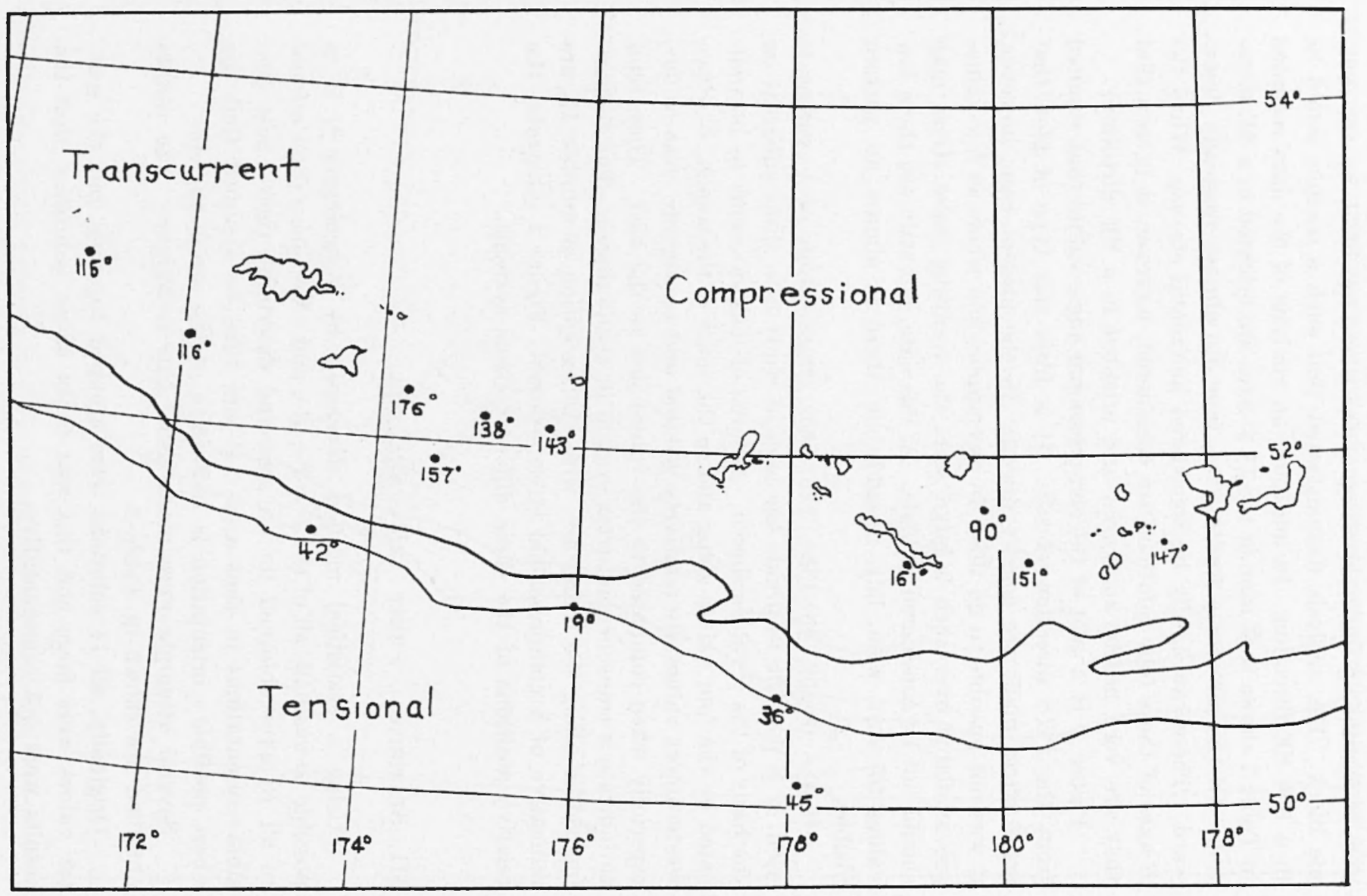

Fig. 4 - Compressional angle values and the stress systems they indicate. 
TABI 42

Summary of the Statistical Seismic Analysis Results for the Rat Islands Area.

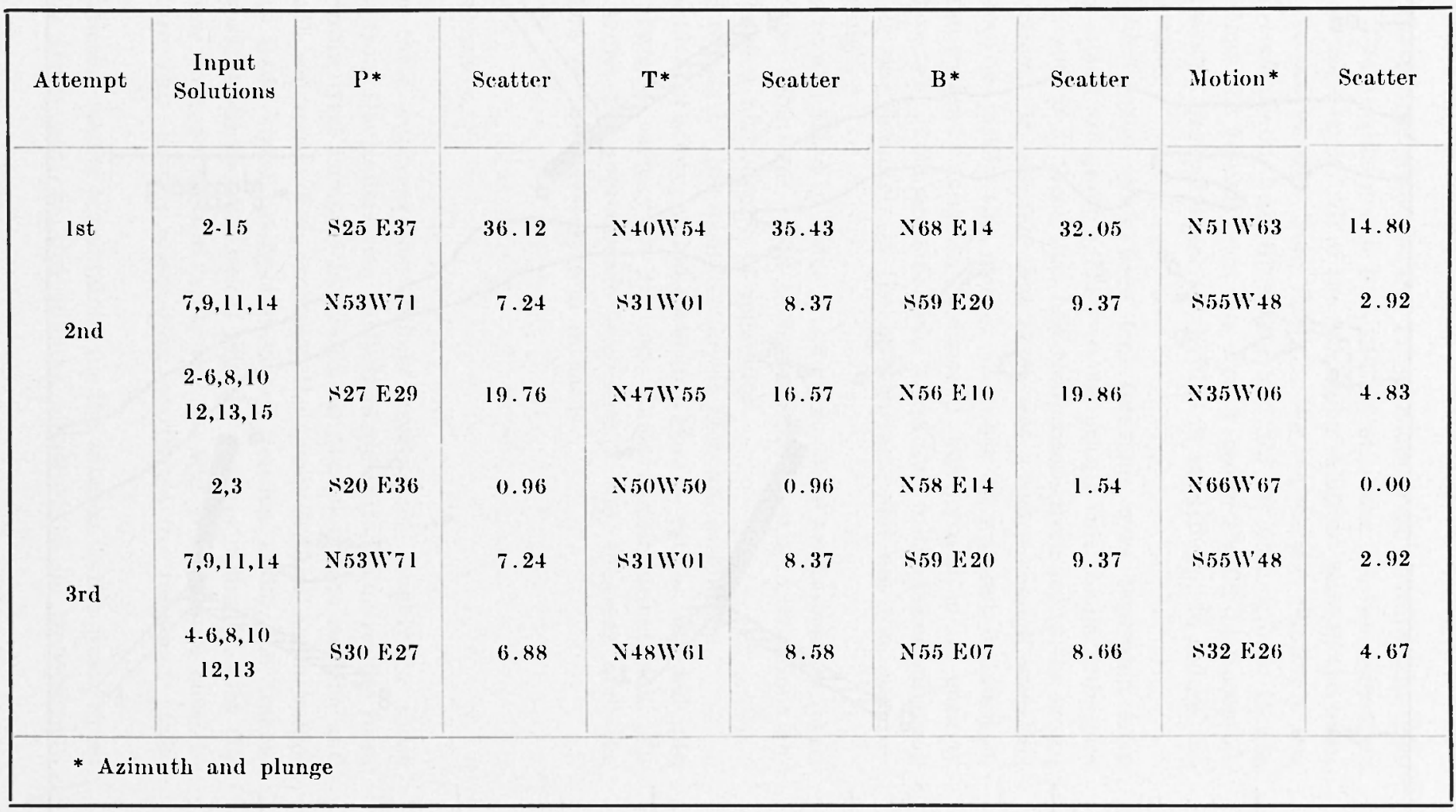




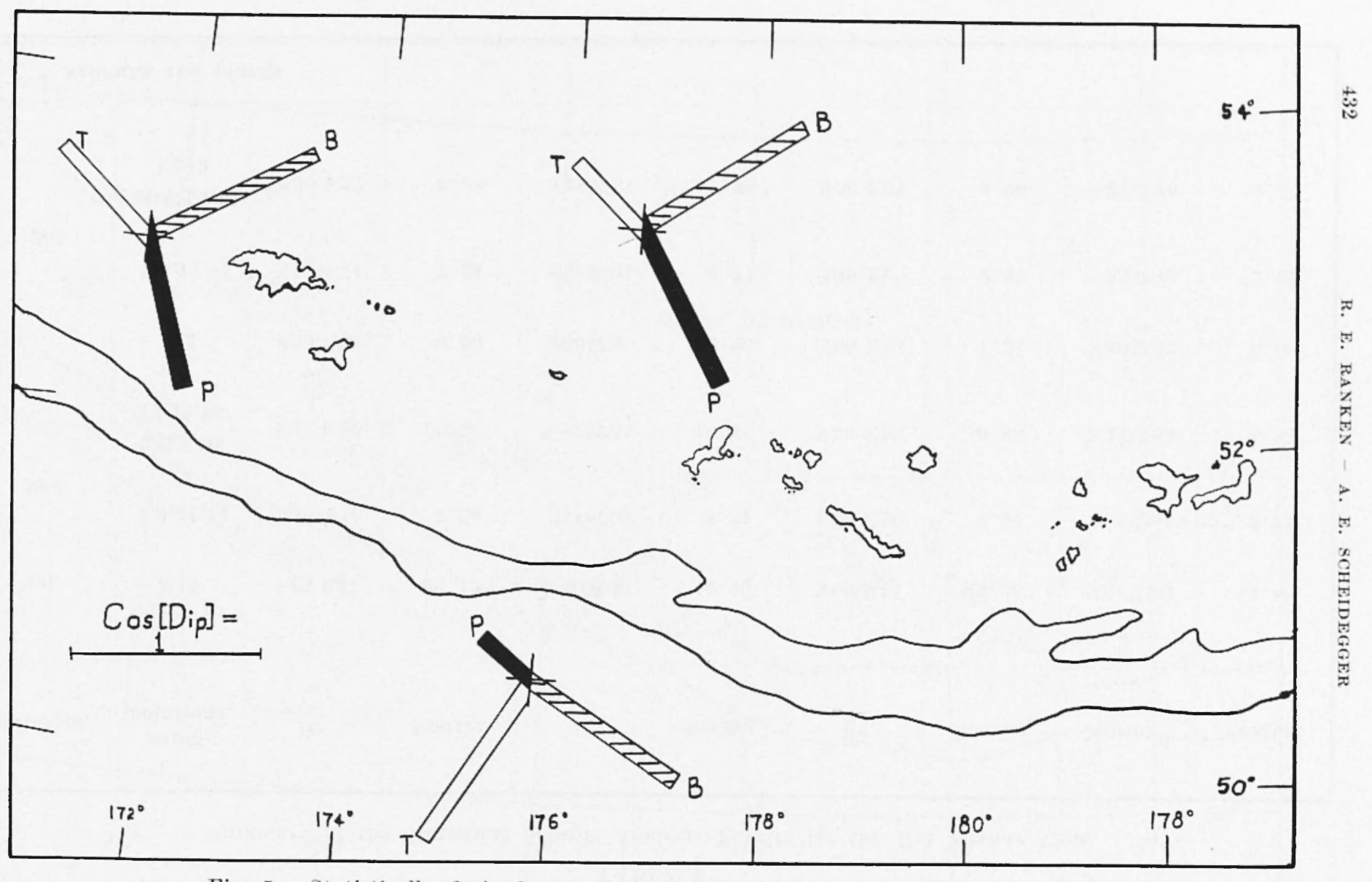

Fig. 5 - Statistically derived stress field orientations for the Rat Islands area. 
In the second attempt the 14 solutions were divided into two groups. The smaller group consisted of solutions for the epicenters located on the trench. All of the remaining solutions were in the other group. As can be seen from Table 2, the scatter was relatively low for the trench group, but still rather high for the other group. It was decided that the results from the trench group should be accepted, and the second group further subdivided in an attempt to reduce the scatter further.

In this second subdivision two solutions were separated from the large island arc group. The two comprising this smaller subgroup were \# 2 and \#3, those that had compressional angles in the transcurrent range. It was felt that there was a sharp enough variation in $\gamma$ values to justify this choice. Number 15 was not included in this "transcurrent" subgroup because it was located in an entirely different section of the area, nor was it included in the other subgroup because it was definitely in the transcurrent, and not the compressional, range.

The results listed in Table 2 show that small seatter values result for all three subgroups. This indicates that the axis orientations obtained have a high degree of reliability.

The results of this seismic analysis then are as follows:

The area of study, as indicated in Figure 1, can be divided into three subareas, each with its own stress system orientation. Figure 5 shows the approximate locations of the subareas and the orientation of the stress system in each.

\section{Discussion.}

The three subareas just defined correspond roughly to those obtained from the isallo stress analysis of the data. The results from these two analyses compare favorably for the island are subarea and the trench subarea. For example, the compressional angle values from the isallo stress analysis indicated tension under the trench. For this same subarea statistical seismic analysis indicated that the $P$-axis was close to vertical while the $T$ - and $B$-axes were close to horizontal. This is the orientation attributed to tensional stress systems.

Conflicting results are obtained for the subarea to the west. From the isallo stress analysis this subarea appeared to be transcurrent. 
However, the orientation of the "best " axes suggests a compressional stress system similar to that of the island arc subarea.

Observations of other researchers into the tectonies of this area may prove useful at this point. I paper by Jordan, Lander, and Black (?) tends to support the transcurrent hypothesis. They say that the presence of numerous epicenters located far to the south of the island arc-trench system between $170^{\circ}$ and $173^{\circ} \mathrm{E}$, plus the sharp western boundary of the epicentral zone, "suggest the presence of a structural element transverse to the main are structure and bounded ded on the west by a major fracture zone". If the stress system in this subarea is simply a continuation of the island are system, as suggested by the statistical seismic results, it seems unlikely that the unusual features present would exist.

Another point of controversy arises in the easternmost portions of the area. The final results of both methods used in this analysis were reached withont ntilizing the somewhat anomalous data from fault plane solution 15. Located among the other solutions whose axes orientations indicated compressional systems, solution 15 is unique in that its $l^{\prime}-, T$-, and $B$-axis orientation is almost the ideal example of a transcurrent stress system. When conclusions are based on the 11 fault plane solutions and their locations, solution 15 tends to appear as a lluke, an isolated case, having little or no significance. However, if additional physical data are incorporated as was done by Stauder $\left({ }^{5}\right)$, solution 15 can become more significant. As can be seen from Figure 1, the system of epicenters has a sharp boundary, similar to the one in the west, at about $180^{\circ}$ longitude. This fact, coupled with the presence of solution 15 , would seem to indicate another transcurrent type feature transverse to the island are-trench system.

In the light of these new observations the conclusions of this study will be as follows:

The area of study can be divided into four subareas, each with its own local stress system. The two central subareas obtained from both the isallo stress analysis and the statistical seismic analysis will be retained. The subarea to the west is designated transcurrent despite the results of the statistical seismic analysis. It is felt that the physical evidence pointed out by Jordan et al. (7) outweighs that indicated by this analysis. A fourth subarea to the east is added. It, like the one to the west, is designated as a transcurrent area. Figure 6 shows the area of study divided into the now four subareas and the stress system in each. 


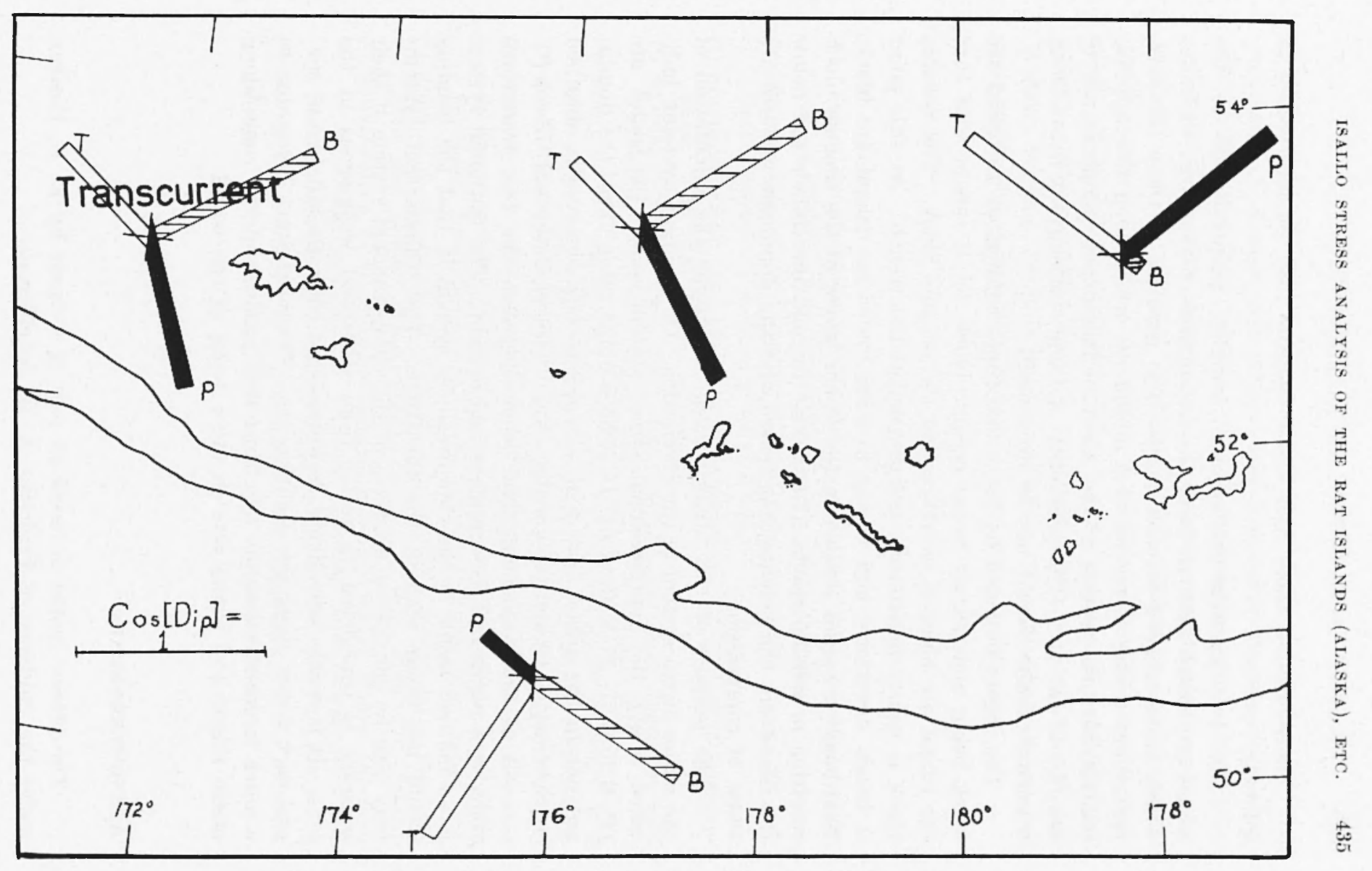

Fig. 6 - Stress field orientations derived for the Rat Islands area. 
The effects of these four stress systems may be interpreted as follows:

The two transcurrent systems, roughly perpendicular to the island arc-trench system, form the boundaries of two large "blocks" which move relative to each other. The presence of these transcurrent zones makes it possible for motion to occur along this approximately 500-mile section of the Aleutian Island arc independently of the rest of the arc. The possibility of these transcurrent zones being transform faults should not be discounted.

The region bounded by these two zones consists of an island arc block being underthrust by an oceanic block, or, it can be said that the island arc block is overthrusting the oceanic block. The oceanic block is nearly horizontal until it reaches the trench. At this point it bends downward and begins to slide under the island arc block. This bending causes tension in the upper layers of the oceanic block resulting in tension cracks and faults. Beyond the trench and below the island arc the bending has ceased and the dominant features are those of compression.

The purpose of this analysis is to determine the orientation of the major stress system in the given area. Of the four systems indicated above the compressional stress system under the island are ( $P$ : S $30 \mathrm{E} 27, T: \mathrm{N} 48 \mathrm{~W} 61, B: \mathrm{N} 55 \mathrm{E} 07$ ) is most likely the dominant one in the area. This is in agreement with the results obtained by Scheidegger $\left({ }^{8}\right)$ and the "wedge "hypothesis of Gates and Gibson $\left({ }^{9}\right)$.

All of the movement that occurs between the two transverse zones is a result of this compressional system. The tensional system is an indirect result of the rompressional system in that the bending would not oceur without the thrusting. The transeurrent systems may also be considered products of the compressional system if their presence is considered to result from structural weaknesses in the area. It is much more likely, however, that they are but two of several such zones along the Aleutian arc. Their existence being due to a much larger stress action like those that produce similar zones along ocean ridges and island arcs in other parts of the world.

\section{ACKNOWLEDGMENTS.}

The present paper is based on part of a thesis by R. E. Ranken under the guidance of Professor A. E. Scheidegger. 
The authors wish to acknowledge their indebtedness to the Department of Mining, Metallurgy and Petroleum Engineering of the University of Illinois without whose financial support this paper could not have been written. The numerical computations were performed on the University of Illinois IBM $7094-1401$ and $360 \mathrm{com-}$ puter systems operating under grants of the National Science Foundation. It is a pleasure to acknowledge the support received from this agency. The authors also wish to express their gratitude to Father William Stauder of Saint Louis University for allowing the use of the results of his Rat Islands study prior to its publication.

\section{REFERENCES}

(1) Lensen G. J., Measurement of Compression and Tension: Some Applications. "N.Z.J. Geol. Geophys.", 1 (3), 565-570, (1958).

(2) SCHEIdegger A. E., Geometrical Significance of Isallo Stress, "N.Z.J. Geol. Geophys. ", 6 (2), 221-227, (1963).

(3) Scinemdegger A. E., Isallo Stress Prospecting. "Zeitschrift Fur Geophysik ", 32 (4), 183-199, (1966).

(4) Anderson E. M., The Dynamics of Faulting and Dyke Formation with Application to Britain. Oliver and Boyd, Edinburgh, (1942).

${ }^{5}$ ) Stauder W., Mechanism of the Rat Island Earthquake Sequence of $t$ February 196.5 with Relation to Island Arcs and Sea-Roor Spreading. "J. Geophys. Research", 73 (12), 3847-3858, (1968).

${ }^{(6)}$ ScInembegger A. E., The Tectonic Stress and Tectonic Motion Direction in Europe and Western A sia as Calculated from Earthquake Fault Plane Solutions. "Seism. Soc. Am. Bull.", 54 (5), 1519-1528, (1964).

(7) Jordan J. N., I Lander J. F., Black R. Aftershocks of the + February 1965 Rat Islands Earthquake. "Science", 148, 1323-1325, (1965).

$\left.{ }^{8}\right)$ Schempgger A. E., The Tectonic Stress and Tectonic Motion Direction in the Pacific and Adjacent Areas as Calculated from Earthquake Fault Plane Solutions. "Seism. Soc. Am. Bull.". 55 (1) 147-152, (1965).

$\left({ }^{9}\right)$ Gates O., Gibson W., Interpretation of the Configuration of the Aleutian Ridge. "Geol. Soc. Am. Bull.", 67 (2), 127-146, (1956). 